\title{
Rotavirus P[8] Infections in Persons with Secretor and Nonsecretor Phenotypes, Tunisia
}

\author{
Siwar Ayouni, Khira Sdiri-Loulizi, \\ Alexis de Rougemont, Marie Estienney, \\ Katia Ambert-Balay, Serge Aho, Sabeur Hamami, \\ Mahjoub Aouni, Mohamed Neji-Guediche, \\ Pierre Pothier, Gaël Belliot
}

To determine whether rotavirus infections are linked to secretor status, we studied samples from children in Tunisia with gastroenteritis. We phenotyped saliva for human blood group antigens and tested feces for rotavirus. Rotavirus was detected in 32/114 patients. Secretor genotyping showed that $P[8]$ rotavirus infected secretors and nonsecretors, and infection correlated with presence of Lewis antigen.

E ach year, millions of persons worldwide suffer from acute gastroenteritis. Group A rotavirus is the leading cause of acute gastroenteritis in children $<5$ years of age. The disease causes $\approx 453,000$ deaths annually, mostly in developing countries (1); however, the number of cases has declined in industrialized countries where vaccines have been recommended (2).

Recent findings showed that human blood group antigens (HBGAs) might be involved in rotavirus attachment to intestinal cells $(3,4,5,6)$. Expression of the HBGAs (A, $\mathrm{B}, \mathrm{H}$, and Lewis antigens) in saliva and on the surface of intestinal cells is driven by the FUT2 (A, B, and $\mathrm{H}$ antigens [secretor]) and FUT3 (Lewis antigens) genes, which express type 2 and type 3 fucosyltransferases, respectively. Approximately $20 \%$ of the white population is homozygous for a recessive point mutation of the FUT2 gene, which leads to the absence of $\mathrm{A}, \mathrm{B}$, and $\mathrm{H}$ antigen expression, also called the nonsecretor phenotype. There is also a Lewis-negative phenotype resulting from various mutations of the FUT3 gene (7).

The entry of rotavirus into cells involves several factors. Human and porcine rotaviruses could specifically interact with $\mathrm{H}$ antigen type 1, Lewis b antigen, or Lewis a antigen through their viral protein (VP) 8 and VP5 during the attachment phase $(3,4,8)$. Of note, the HBGA

Author affiliations: National Reference Center for Enteric Viruses, Dijon, France (S. Ayouni, A. de Rougemont, M. Estienney, K. Ambert-Balay, P. Pothier, G. Belliot); Monastir University, Monastir, Tunisia (S. Ayouni, K. Sdiri-Loulizi, M. Aouni); Public Hospital of Dijon, Dijon (S. Aho); Hospital Fattouma Bourguiba, Monastir (S. Hamami, M. Neji-Guediche)

DOI: http://dx.doi.org/10.3201/eid2111.141901 binding profile is $\mathrm{P}$ genotype-dependent (4), and rotavirus infection correlates with the secretor and partial secretor phenotype (i.e., with active FUT2 gene status) $(5,6,9)$. However, in some studies, no association has been observed between HBGAs from blood cells (10), including Lewis antigens (11), and rotavirus infection. A recent epidemiologic survey of children in the region of Monastir, Tunisia, gave us the opportunity to determine whether rotavirus infections in children could be linked to secretor status and HBGAs.

\section{The Study}

During November 2011-February 2012, feces and saliva samples were collected from 114 children $<6$ years of age who were seen for acute gastroenteritis at the Fattouma Bourguiba children's hospital (Monastir). For 98 of these patients, blood samples were also collected at symptom onset for FUT2 genotyping by sequencing for the A385T and G428A nonsense mutations from total blood DNA (9). The study was approved by the Ethics Committee of the Fattouma Bourguiba University Hospital in Monastir, and informed consent was obtained from the parents of the 114 study participants.

The feces were first screened for the presence of group A rotavirus antigen by using the Premier Rotaclone detection kit (Meridian Bioscience, Inc., Paris, France). The remainder of the suspension was used for the extraction of nucleic acids by using a Nuclisens easyMAG system (bioMérieux, Marcy l'Étoile, France) according to the manufacturer's instructions. RNA was eluted in a final volume of $110 \mathrm{~mL}$ and used for the molecular detection and typing of rotavirus. Norovirus PCR detection is described elsewhere (12).

Samples positive for rotavirus by ELISA were further confirmed and genotyped by PCR as described previously (online Technical Appendix Table, http://wwwnc.cdc.gov/ EID/article/21/11/14-1901-Techapp1.pdf). Of the 114 patients, 32 had confirmed rotavirus infections by ELISA and PCR. Of the 32 confirmed cases, 24 (75\%) occurred during the cold season, and $26(80 \%)$ occurred in children $<14$ months of age; the mean age for infected persons was 8.1 months. We used ELISAs to screen the saliva of rotaviruspositive patients for A and B antigens (anti-A and anti-B mouse IgG from DIAGAST, Loos, France), $\mathrm{H}$ antigen (anti-H specific IgM from Thermo Fisher Scientific, Villebon sur Yvette, France), and Lewis antigens (anti-Lewis a [clone 7LE] and anti-Lewis b [clone 2-25LE] hybridoma 
Table 1. Distribution of rotavirus and norovirus cases among 114 children < 6 years of age by ABO blood group, Lewis phenotype status, and nonsecretor status, Tunisia, November 2011-February 2012*

\begin{tabular}{|c|c|c|}
\hline Phenotype & No. rotavirus-positive patients & No. norovirus-positive patients \\
\hline \multicolumn{3}{|c|}{$\mathrm{ABO}$ and Lewis antigen distribution in patients, $\mathrm{n}=90$} \\
\hline Le+, $n=37$ & 12 & 21 \\
\hline Le- $-\mathrm{n}=1$ & 0 & 0 \\
\hline \multicolumn{3}{|l|}{ A } \\
\hline $\mathrm{Le}+, \mathrm{n}=26$ & 10 & 7 \\
\hline Le-, $n=1$ & 0 & 0 \\
\hline \multicolumn{3}{|l|}{$B$} \\
\hline Le+, $n=16$ & 4 & 4 \\
\hline Le-,$n=3$ & 0 & 2 \\
\hline \multicolumn{3}{|l|}{$A B$} \\
\hline Le+, $n=6$ & 2 & 1 \\
\hline Le-, $\mathrm{n}=0$ & 0 & 0 \\
\hline \multicolumn{3}{|c|}{ Nonsecretor group, Lewis antigen status, $n=24$} \\
\hline Positive, $n=24$ & 4 & 7 \\
\hline Negative, $n=0$ & 0 & 0 \\
\hline Total & 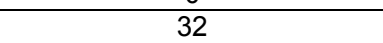 & 42 \\
\hline
\end{tabular}

supernatants; gift from Jacques Bara, INSERM U673). Among the secretor phenotype-positive rotavirus patients, no blood group antigen nor $\mathrm{P}$ or $\mathrm{G}$ genotypes (in feces specimens) were significantly overrepresented. For comparison, we assessed the distribution of ABO blood groups and Lewis antigens among patients with norovirus and rotavirus; no statistical difference was found (Table 1). Rotavirus infection was observed only in Lewis antigen-positive patients ( $p=0.017$, exact logistic regression); however, the prevalence of the Lewis antigen-negative phenotype in the population was low.
Among the 32 rotavirus isolates, 30 were genotype $\mathrm{P}[8]$ and 2 were genotype P [4] (Table 2). G9, G3, and G1 were the most common genotypes and were detected in $13(40 \%), 8$ (25\%), and 7 (21\%) of the cases, respectively. The G genotype could not be determined for $1 \mathrm{P}[8]$ genotype isolate. Genotypes G1, G3, G4, and G9 were all associated with the P[8] genotype, and genotype $\mathrm{G} 2$ was associated with the $\mathrm{P}[4]$ genotype. Rotavirus G9P[8] strains were predominant $(n=12)$, followed by G3P $[8](n=8)$ and G1P $[8](n=7)$ strains.

For $3 \mathrm{G} 9 \mathrm{P}[8]$ and $1 \mathrm{G} 3 \mathrm{P}[8]$ rotavirus-positive patients, saliva samples were negative for Lewis $b$ antigen

Table 2. Distribution of $A B O$ blood groups and Lewis antigens among 32 children $<6$ years of age infected with various rotavirus strains in Monastir, Tunisia, November 2011-February 2012*

\begin{tabular}{|c|c|c|c|c|c|c|c|c|c|c|}
\hline \multirow{3}{*}{$\begin{array}{l}\text { Isolated rotavirus } \\
\text { strain, patient FUT2 } \\
\text { genotype }\end{array}$} & \multicolumn{8}{|c|}{ No. patients by $A B O$ blood group and Lewis antigen status $\dagger$} & \multirow{2}{*}{\multicolumn{2}{|c|}{$\begin{array}{l}\text { No. nonsecretor } \\
\text { patients }\end{array}$}} \\
\hline & \multicolumn{2}{|c|}{0} & \multicolumn{2}{|c|}{$\mathrm{A}$} & \multicolumn{2}{|c|}{$\mathrm{B}$} & \multicolumn{2}{|c|}{$A B$} & & \\
\hline & Le+ & Le- & Le+ & Le- & $\mathrm{Le}^{+}$ & Le- & $\mathrm{Le}^{+}$ & Le- & $\mathrm{Le}+$ & Le- \\
\hline G9P[8] & 4 & 0 & 1 & 0 & 2 & 0 & 2 & 0 & 3 & 0 \\
\hline $\mathrm{Se} / \mathrm{Se}$ & 0 & 0 & 1 & 0 & 1 & 0 & 1 & 0 & 0 & 0 \\
\hline Se/se & 4 & 0 & 0 & 0 & 1 & 0 & 1 & 0 & 0 & 0 \\
\hline se/se & 0 & 0 & 0 & 0 & 0 & 0 & 0 & 0 & 3 & 0 \\
\hline G3P[8] & 1 & 0 & 4 & 0 & 2 & 0 & 0 & 0 & 1 & 0 \\
\hline $\mathrm{Se} / \mathrm{Se}$ & 0 & 0 & 2 & 0 & 1 & 0 & 0 & 0 & 0 & 0 \\
\hline Se/se & 1 & 0 & 1 & 0 & 1 & 0 & 0 & 0 & 0 & 0 \\
\hline se/se & 0 & 0 & 0 & 0 & 0 & 0 & 0 & 0 & 1 & 0 \\
\hline G1P[8] & 4 & 0 & 3 & 0 & 0 & 0 & 0 & 0 & 0 & 0 \\
\hline $\mathrm{Se} / \mathrm{Se}$ & 0 & 0 & 0 & 0 & 0 & 0 & 0 & 0 & 0 & 0 \\
\hline Se/se & 4 & 0 & 2 & 0 & 0 & 0 & 0 & 0 & 0 & 0 \\
\hline G4P[8] & 1 & 0 & 1 & 0 & 0 & 0 & 0 & 0 & 0 & 0 \\
\hline Se/se & 0 & 0 & 1 & 0 & 0 & 0 & 0 & 0 & 0 & 0 \\
\hline G2P[4] & 2 & 0 & 0 & 0 & 0 & 0 & 0 & 0 & 0 & 0 \\
\hline $\mathrm{Se} / \mathrm{Se}$ & 1 & 0 & 0 & 0 & 0 & 0 & 0 & 0 & 0 & 0 \\
\hline $\mathrm{P}[8]$ & 0 & 0 & 1 & 0 & 0 & 0 & 0 & 0 & 0 & 0 \\
\hline $\mathrm{Se} / \mathrm{Se}$ & 0 & 0 & 1 & 0 & 0 & 0 & 0 & 0 & 0 & 0 \\
\hline Total & 12 & 0 & 10 & 0 & 4 & 0 & 2 & 0 & 4 & 0 \\
\hline $\mathrm{Se} / \mathrm{Se}$ & 1 & 0 & 4 & 0 & 2 & 0 & 1 & 0 & 0 & 0 \\
\hline Se/se & 9 & 0 & 4 & 0 & 2 & 0 & 1 & 0 & 0 & 0 \\
\hline se/se & 0 & 0 & 0 & 0 & 0 & 0 & 0 & 0 & 4 & 0 \\
\hline
\end{tabular}

*Le+, positive for Lewis antigen; Le-, negative for Lewis antigen; Se/Se, homozygous secretor; Se/se, heterozygous secretor; se/se, nonsecretor. †Human blood group antigen distribution was determined by using a typing assay with saliva samples. 
(mean absorbance at $450 \mathrm{~nm}$ was 0.25 ) and positive for the presence of Lewis a antigen (mean absorbance at $450 \mathrm{~nm}$ was 3.67), suggesting that the patients were Lewis-positive and nonsecretors. A total of 98 blood samples were genotyped by sequencing of the FUT2 gene. Homozygous secretor, heterozygous secretor, and nonsecretor genotypes represented $23.47 \%, 54.08 \%$, and $22.45 \%$ of the cohort, respectively. All nonsecretors $(\mathrm{n}=22)$ harbored the G428A mutation. The A385T mutation was absent. Blood samples were available for 28 of the 32 rotavirus-positive patients. Of these 28 patients, 24 were homozygous and heterozygous secretors and 4 were nonsecretors. Because rotaviruses were P- and G-typed by PCR using VP4- and VP7-specific primers, we further confirmed the presence of rotavirus in samples from nonsecretor patients. For 3 of the samples, we used a TaqMan-based quantitative reverse transcription PCR with VP2-specific primers to detect rotavirus (13), and for 2 rotavirus isolates (GenBank accession nos. KP862856 and KP862857) for which feces samples were still available, we confirmed the P[8] genotype by sequencing.

\section{Conclusions}

Our findings show that rotaviruses can infect secretor and nonsecretor Lewis antigen-positive persons, which suggests that rotavirus infection is not associated with the secretor phenotype or HBGA type. However, it should be noted that one limitation of our study was the small size of our cohort. A larger number of cases might provide new insights about the affinity of rotavirus toward certain types of HBGAs; a larger study with a more robust statistical analysis might confirm that rotavirus infections only occur in Lewis antigen-positive persons. In addition, we detected genotype $\mathrm{P}[8]$ rotavirus infection in both secretor and nonsecretor patients; this finding was not observed in previous studies $(5,6,9)$. $\mathrm{P}[8]$ infection of nonsecretors might be associated with preexisting health conditions, and healthy nonsecretors might never be infected by $\mathrm{P}[8]$ rotavirus.

We and others $(3,4,6)$ have characterized the secretor and Lewis phenotypes related to infection by rotaviruses. The interaction between rotavirus particles and HBGAs might constitute the first step in the attachment to the cell before internalization of the virus particle, after binding with integrins $(4,5)$. However, other types of ligand, such as non-HBGA ligands and bacteria from intestinal flora, might also play a role during the infection process, as recently shown for noroviruses $(14,15)$.

In conclusion, our data and that of others show that rotavirus infection might be correlated with genetic factors, such as HBGAs. Further studies will be required to determine the exact role of HBGA ligands and other ligands in rotavirus infection.

\section{Acknowledgments}

We thank Jacques Bara for kindly providing us with Lewisspecific monoclonal antibodies; Philippe Daval, Céline Fremy, and the National Reference Center for Enteric Viruses for their technical support; and Philip Bastable for editorial assistance.

This study was supported by the National Reference Center for Enteric Viruses and the Public Hospital of Dijon, France. A fellowship from Campus France was awarded to S.A. (PHCUTIQUE program).

Ms. Ayouni is currently a PhD student at the National Reference Center for Enteric Viruses (Dijon, France). Her research interests focus on the relation between human blood group antigens and enteric viruses, mainly rotavirus and norovirus.

\section{References}

1. Tate JE, Burton AH, Boschi-Pinto C, Steele AD, Duque J, Parashar UD, et al. 2008 estimate of worldwide rotavirusassociated mortality in children younger than 5 years before the introduction of universal rotavirus vaccination programmes: a systematic review and meta-analysis. Lancet Infect Dis. 2012; 12:136-41. http://dx.doi.org/10.1016/S1473-3099(11)70253-5

2. Lopman BA, Payne DC, Tate JE, Patel MM, Cortese MM, Parashar UD. Post-licensure experience with rotavirus vaccination in high and middle income countries; 2006 to 2011. Curr Opin Virol. 2012;2:434-42. http://dx.doi.org/10.1016/j.coviro.2012.05.002

3. Hu L, Crawford SE, Czako R, Cortes-Penfield NW, Smith DF, Le Pendu J, et al. Cell attachment protein VP8* of a human rotavirus specifically interacts with A-type histo-blood group antigen. Nature. 2012;485:256-9. http://dx.doi.org/10.1038/ nature 10996

4. Huang P, Xia M, Tan M, Zhong W, Wei C, Wang L, et al. Spike protein VP8* of human rotavirus recognizes histo-blood group antigens in a type-specific manner. J Virol. 2012;86:4833-43. http://dx.doi.org/10.1128/JVI.05507-11

5. Nordgren J, Sharma S, Bucardo F, Nasir W, Gunaydin G, Ouermi D, et al. Both Lewis and secretor status mediate susceptibility to rotavirus infections in a rotavirus genotypedependent manner. Clin Infect Dis. 2014;59:1567-73. http://dx.doi.org/10.1093/cid/ciu633

6. Van Trang N, Vu HT, Le NT, Huang P, Jiang X, Anh DD. Association between norovirus and rotavirus infection and histo-blood group antigen types in Vietnamese children. J Clin Microbiol. 2014;52:1366-74. http://dx.doi.org/10.1128/ JCM.02927-13

7. Grahn A, Elmgren A, Aberg L, Svensson L, Jansson PA, Lonnroth P, et al. Determination of Lewis FUT3 gene mutations by PCR using sequence-specific primers enables efficient genotyping of clinical samples. Hum Mutat. 2001;18:358-9. http://dx.doi.org/10.1002/humu.1204

8. Blanchard H, Yu X, Coulson BS, von Itzstein M. Insight into host cell carbohydrate-recognition by human and porcine rotavirus from crystal structures of the virion spike associated carbohydratebinding domain (VP8*). J Mol Biol. 2007;367:1215-26. http://dx.doi.org/10.1016/j.jmb.2007.01.028

9. Imbert-Marcille BM, Barbe L, Dupe M, Le Moullac-Vaidye B, Besse B, Peltier C, et al. A FUT2 gene common polymorphism determines resistance to rotavirus A of the $\mathrm{P}[8]$ genotype. J Infect Dis. 2014;209:1227-30. http://dx.doi.org/10.1093/infdis/jit655

10. Yazgan H, Keles E, Gebesce A, Demirdoven M, Yazgan Z. Blood groups and rotavirus gastroenteritis. Pediatr Infect Dis J. 2013;32:705-6. http://dx.doi.org/10.1097/INF.0b013e318288a48f 
11. Ahmed T, Lundgren A, Arifuzzaman M, Qadri F, Teneberg S, Svennerholm AM. Children with the Le $(\mathrm{a}+\mathrm{b}-)$ blood group have increased susceptibility to diarrhea caused by enterotoxigenic Escherichia coli expressing colonization factor I group fimbriae. Infect Immun. 2009;77:2059-64. http://dx.doi.org/10.1128/ IAI.01571-08

12. Kamel AH, Ali MA, El-Nady HG, de Rougemont A, Pothier P, Belliot G. Predominance and circulation of enteric viruses in the region of greater Cairo, Egypt. J Clin Microbiol. 2009;47:1037-45. http://dx.doi.org/10.1128/JCM.01381-08

13. Gutiérrez-Aguirre I, Steyer A, Boben J, Gruden K, Poljsak-Prijatelj M, Ravnikar M. Sensitive detection of multiple rotavirus genotypes with a single reverse transcription-real-time quantitative PCR assay. J Clin Microbiol. 2008;46:2547-54. http://dx.doi.org/10.1128/JCM.02428-07
14. Jones MK, Watanabe M, Zhu S, Graves CL, Keyes LR, Grau KR, et al. Enteric bacteria promote human and mouse norovirus infection of B cells. Science. 2014;346:755-9. http://dx.doi. org/10.1126/science. 1257147

15. Ruvoën-Clouet N, Magalhaes A, Marcos-Silva L, Breiman A, Figueiredo C, David L, et al. Increase in genogroup II.4 norovirus host spectrum by CagA-positive Helicobacter pylori infection. J Infect Dis. 2014;210:183-91. http://dx.doi.org/10.1093/ infdis/jiu054

Address for correspondence: Gaël Belliot, Centre National de Référence des Virus Entériques, Laboratoire de Virologie/Plateau Technique de Biologie/CHU Dijon, 2 rue Angélique Ducoudray, BP37013, 21070

Dijon CEDEX, France; email: gael.belliot@u-bourgogne.fr

\section{February 2015: Complicated Datasets}

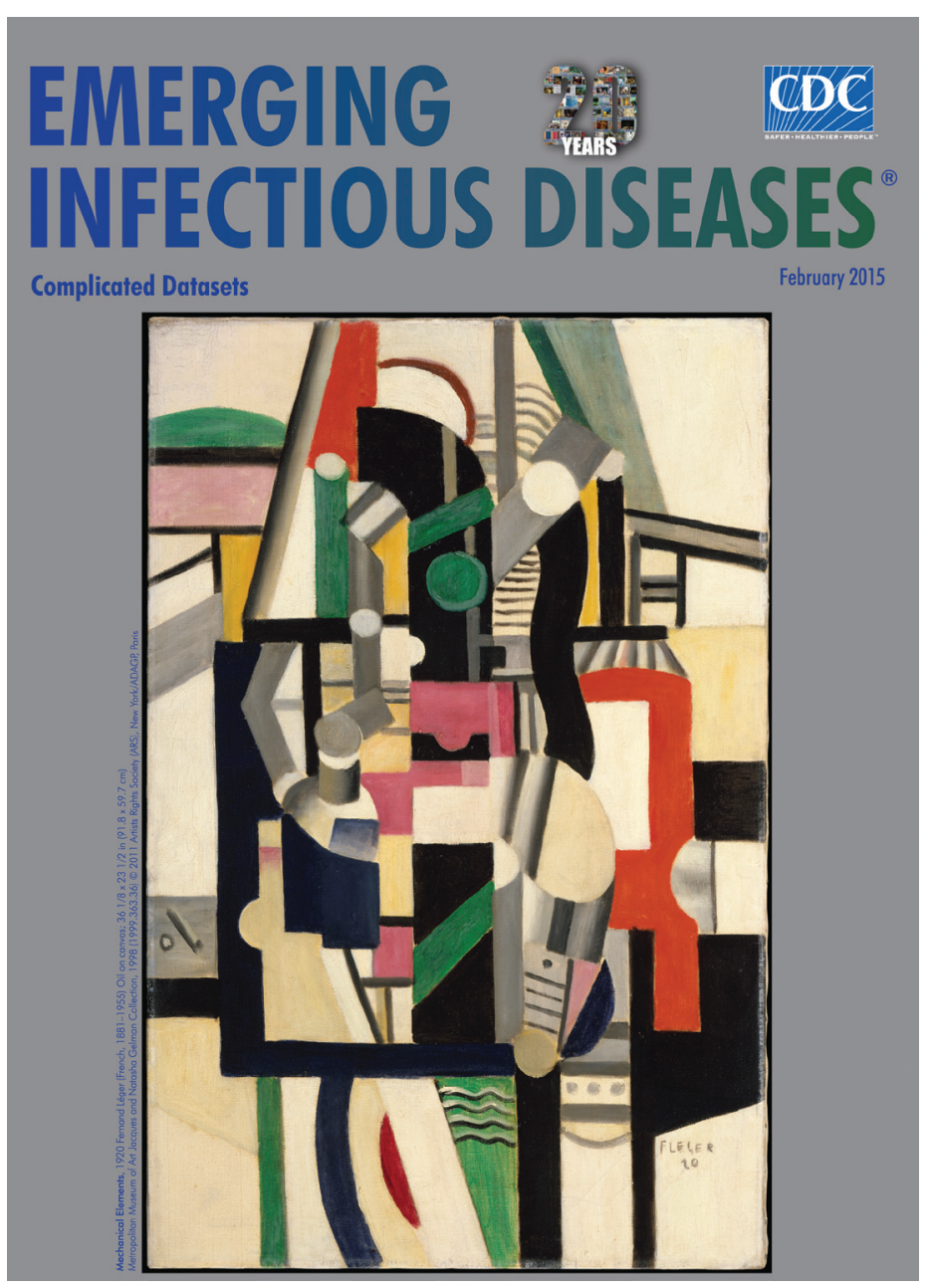

\section{Including:}

- Entry Screening for Infectious Diseases in Humans

- Timing of Influenza $\mathrm{A}(\mathrm{H} 5 \mathrm{~N} 1)$ in Poultry and Humans and Seasonal Influenza Activity Worldwide, 2004-2013

- Quantifying Reporting Timeliness to Improve Outbreak Control

- Tickborne Relapsing Fever, Bitterroot Valley, Montana, USA

- Evidence for Elizabethkingia anophelis Transmission from Mother to Infant, Hong Kong

- $\mathrm{pH}$ Level as a Marker for Predicting Death among Patients with Vibrio vulnificus Infection, South Korea, 2000-2011

\section{http://wwwnc.cdc.gov/eid/content/21/2/contents.htm}

